\title{
Educação e liberdade em Hannah Arendt
}

Vanessa Sievers de Almeida

Universidade de São Paulo

\section{Resumo}

0 presente artigo investiga, numa perspectiva filosófica, a relação entre os conceitos de educação e liberdade nos escritos de Hannah Arendt. Sustenta-se que, embora a autora não aponte para isso, existe em seu pensamento uma relação essencial entre esses conceitos. A interface principal é a natalidade, o fato de seres novos nascerem para um mundo já constituído. Dessa condição existencial decorre, por um lado, a potencial liberdade do ser humano, a capacidade de iniciar algo inesperado e, por outro, a necessidade de acolher os novos num espaço comum que é mais velho do que eles. A tarefa da educação é contribuir para que os "recém-chegados" se apropriem desse mundo que lhes é legado, possibilitando assim que futuramente assumam a responsabilidade por ele. lsso, no entanto, implica na necessidade de arrumar esse lugar, que está "fora dos eixos". A ação educativa nesse sentido, porém, pode ser apenas indireta: sendo que todo ser humano nasce como alguém singular, diferente de qualquer outro, cada um é uma novidade para o mundo e, por isso, é, a princípio, capaz de transformá-lo, começando algo novo. A liberdade, portanto, depende da singularidade de cada pessoa. A educação - que não muda o mundo numa ação direta - pode propiciar às crianças e aos jovens a possibilidade de desenvolver sua singularidade, contribuindo assim para que futuramente possam de fato realizar o dom da liberdade, renovando o mundo que herdaram.

\section{Palavras-chave}

Filosofia da educação - Liberdade - Natalidade - Hannah Arendt. 


\title{
Education and freedom in Hannah Arendt
}

Vanessa Sievers de Almeida

Universidade de São Paulo

\begin{abstract}
The article investigates under a philosophical perspective the relationship between the concepts of education and freedom in Hannah Arendt's writings. It is argued that, although she did not point it out, there exists an essential relationship between these two concepts in her thinking. The main interface here is birth, the fact that new beings are born into a world that is already constituted. Out of this existential condition follows, on one side, the potential freedom of the human being, the capacity to initiate something unexpected and, on the other side, the need to receive the newcomers into a common space that is older than them. The task of education is to help the "newcomers" to embrace the world that is left to them, allowing them to take responsibility for it in the future. This, however, implies the need to tidy up this place, which is "out of its bearings". The educative action in this sense can, however, be only indirect: since every human being is born as someone singular, different from everybody else, each one of them is a novelty to the world and thus in principle capable of transforming it, of starting something new. Freedom, therefore, depends on each person's singularity. Education which does not change the world in a direct action - can give children and youngsters the possibility of developing their singularity, thereby contributing to make them realize in the future the gift of freedom, renewing the world they inherited.
\end{abstract}

\section{Keywords}

Philosophy of education - Freedom - Birth - Hannah Arendt.

Contact:

Vanessa Sievers de Almeida

Rua Hermínio Falcon, 144

07082-620 - Guarulhos - SP

E-mail: vanessa.sievers@terra.com.br 
[...] o homem é livre porque ele é um começo e, assim, foi criado depois que o universo passara a existir [...]. No nascimento de cada homem esse começo inicial é reafirmado, pois em cada caso vem ao mundo já existente alguma coisa nova que continuará a existir depois da morte de cada indivíduo. (Hannah Arendt)

A liberdade do ser humano impõe um desafio à educação. É sobre essa questão que pretendemos refletir no presente artigo, baseando-nos nos escritos da filósofa e pensadora do político Hannah Arendt. Indagaremos de que modo a educação pode contribuir para que a liberdade - a que irrompe ao mundo constituído com o nascimento de cada ser humano possa ser de fato realizada e não permanecer apenas como possibilidade.

Partiremos do ensaio A crise na educação, que se encontra em Entre o passado e o futuro (1990) e que, a nosso ver, não por acaso está na seqüência das reflexões da autora sobre a tradição que preserva o mundo e sobre a liberdade, ou seja, a capacidade de transformá-lo. A educação se insere nesse meio: entre um mundo que é mais velho do que as crianças e o potencial renovador que estas trazem consigo.

Arendt não estabelece uma relação direta entre educação e liberdade. No seu ensaio sobre educação, a ênfase maior recai no papel da tradição e da autoridade, já que a crise na educação está relacionada à ruptura e perda destas. Contudo, sustentamos que existe uma relação essencial entre os seus conceitos de educação e liberdade, sem a qual não é possível compreender o que para ela significa educar. 0 sinal mais claro dessa relação é que ambos os conceitos se sustentam num mesmo alicerce: a natalidade.

No que segue, abordaremos os possíveis desdobramentos dessa interface para uma reflexão sobre o sentido da educação.

\section{A natalidade}

"A essência da educação é a natalidade" (p. 223), explica Arendt (1990). Nesse sentido, educar é acolher as crianças, que nascem para o mundo, mas ainda não o conhecem. Preparamos os "recém-chegados" para que futuramente possam assumir e renovar esse lugar que lhes será legado. Para tanto, é preciso familiarizá-los com o mundo para que possam apreciá-lo a tal ponto que percebam que vale a pena "apostar" nele e se empenhar em sua transformação.

Os novos, a princípio, são capazes de intervir no mundo porque são livres, o que, segundo Arendt (1990), significa que se, por um lado, precisam se inserir numa realidade dada, por outro lado, também podem modificá-la, iniciando algo novo. A liberdade é essa capacidade de fazer um início. Ela é inerente a todo ser humano que veio, ele mesmo, como algo novo ao mundo. "Por constituírem um initium, por serem recém-chegados e iniciadores em virtude do fato de terem nascido, os homens tomam iniciativas, são impelidos a agir" (Arendt, 1983, p. 190). Assim, a potencial liberdade do ser humano decorre de sua natalidade.

A educação, por sua vez, diz respeito a "nossa atitude face ao fato da natalidade: $\mathrm{o}$ fato de todos nós virmos ao mundo ao nascermos e de ser o mundo constantemente renovado mediante o nascimento" (Arendt, 1990, p. 247). Com ela, assumimos a responsabilidade de receber os novos e de contribuir para que num futuro possam desenvolver de fato o dom que lhes é dado por nascimento: a liberdade. Nas palavras de Arendt (1990): preparamos as crianças "com antecedência para a tarefa de renovar um mundo comum" (p. 247).

Assim, a natalidade é o ponto onde educação e liberdade se encontram. Como condição da nossa existência, a natalidade, porém, nos garante apenas a liberdade em potência. A sua realização depende, por um lado, de um espaço no mundo onde ela possa aparecer - e cuidar disso é tarefa da política. A educação, por outro lado, deve assumir a responsabilidade de preparar os novos para a ação livre.

\section{A educação}

A nossa trajetória de vida é efêmera, mas fazemos parte de uma história mais abrangente. 
Ela é anterior a nós e continuará depois. Essa história, entretanto, não é linear e não segue nenhuma "lei", mas acontece por meio da ação dos homens que têm a possibilidade de interromper o que está em andamento e começar algo inteiramente novo. Assim, a natalidade se refere a uma dinâmica entre o mundo, historicamente constituído, e a ação livre de quem o constitui.

Falando e agindo intervimos no mundo dos homens, o qual existia antes de termos nascido; e essa intervenção é como um segundo nascimento, no qual confirmamos o mero fato de termos nascido, assumindo a responsabilidade por ele. (Arendt, 1960, p. 165)

É nesse tempo entre o nascimento biológico, com o qual surge essa potência renovadora, e o momento no qual os novos poderão ativamente assumir sua liberdade e agirão que se insere a educação. Ela, segundo Arendt (1990), tem basicamente duas tarefas: (1) introduzir os novos num mundo que os antecede e sempre é mais velho do que eles; e (2) contribuir para que eles desenvolvam sua singularidade, aquilo que têm de único e novo para o mundo.

\section{Conservar o mundo}

0 mundo, para Arendt, não é simplesmente o que nos rodeia, mas um espaço construído pelo trabalho e constituído pela ação. Construções e artefatos garantem aos seres humanos um lugar duradouro no meio da vida e da natureza, onde tudo aparece e desaparece, isto é, vida e morte se alternam constantemente. Nesse espaço construído, os seres humanos podem criar formas de convivência e interação que vão além da preocupação com a mera sobrevivência ou continuidade da espécie, embora as necessidades básicas não deixem de existir e precisem ser supridas antes de termos a possibilidade de participar no mundo. No entanto, Arendt (1983) enfatiza que nossa existência abrange esferas onde essas necessidades não são os fatores determinantes por excelên- cia e que isso é específico do ser humano, em contraposição ao resto da natureza.

Sendo assim, Arendt (1983) distingue entre a atividade humana que se preocupa com as necessidades vitais - o labor - e as atividades que dizem respeito ao mundo humano - o trabalho, a ação e o pensamento. 0 labor corresponde a uma das condições da nossa existência na Terra: a vida. Para cuidar da nossa vida, precisamos satisfazer nossas necessidades, assim como o faz também qualquer outra espécie de seres vivos. Para satisfazer a fome, por exemplo, produzimos alimentos que, em seguida, consumimos. Esse ciclo de produção e consumo, originariamente ligado aos processos biológicos, na modernidade, extrapola cada vez mais a satisfação das necessidades meramente biológicas e se estende a outras dimensões. Não consumimos apenas alimentos, mas estilos de vida, produtos “culturais”, emoções, imagens. Contudo, embora o processo de produção e consumo seja cada vez mais exacerbado, a lógica que lhe é inerente continua sendo a mesma: a satisfação das necessidades sejam essas biológicas ou não.

0 trabalho, por sua vez, está relacionado à mundanidade do ser humano, isto é, à necessidade de construir um espaço duradouro no meio de uma natureza onde tudo aparece e desaparece constantemente. Assim, o ser humano fabrica artefatos, objetos de uso e espaços que não se destinam ao consumo imediato, mas que the possam ser úteis e que lhe garantem uma estabilidade para ter um lar que ele não possui por natureza.

A ação é a atividade mais especificamente humana. 0 que nos impele a agir é a condição da pluralidade dos seres humanos. A ação diz respeito à convivência entre seres humanos, que são singulares, mas não vivem no singular e sim no plural, ou seja, com outros. Essa é a característica fundamental da existência humana.

A pluralidade possibilita aos seres humanos constituírem um âmbito de ação no qual cada um pode se revelar em atos e palavras, o que não faria sentido de modo isolado, mas ganha sua 
relevância numa esfera que se estabelece entre as pessoas. É com suas ações que as pessoas constantemente criam e recriam o "espaço-entre" e, assim, estabelecem um mundo comum.

É corrente pensar que algo diz respeito à comunidade simplesmente porque é do interesse da maioria das pessoas que a compõem. Muitas vezes, entende-se que bens, instituições ou objetivos da comunidade são importantes porque beneficiam um grande número de indivíduos e, assim, representam de alguma forma uma soma de elementos advindos de projetos individuais. Essa visão, entretanto, nada tem a ver com o conceito de mundo comum em Arendt. Muito pelo contrário: conforme a autora, é importante compreender que há coisas e assuntos essenciais que só existem porque são comuns.

Podemos nos valer da ajuda de um outro autor para entender melhor o que vem a ser um bem comum. Charles Taylor (2000) explica que, numa comunidade, as pessoas certamente podem constatar que seus projetos de vida individuais em algum ponto convergem e que, portanto, é mais eficaz juntarem as forças do que agirem isoladamente. Há, portanto, bens convergentes, que podem ser proporcionados mais facilmente de modo coletivo. Um exemplo disso é o corpo de bombeiros. É mais fácil mantê-lo de modo coletivo. No entanto, se um indivíduo tivesse a possibilidade de ter o seu próprio corpo de bombeiros, ele se beneficiaria da mesma maneira (ou talvez mais). 0 benefício do corpo de bombeiros, portanto, em última instância diz respeito aos indivíduos.

Taylor (2000) adverte, porém, que disso não podemos deduzir que todos os bens beneficiarão indivíduos. Há bens cujos benefícios não podem ser decompostos em partes individuais e que só passam a existir ou a fazer sentido enquanto bens comuns. A linguagem talvez seja o exemplo mais claro de um bem comum. 0 ato de fala particular corresponde a um indivíduo, mas ao mesmo tempo pressupõe um código comum. Certamente as falas individuais contribuem para manter e renovar constantemente esse código: elas, entretanto, só ganham sen- tido no contexto mais amplo da linguagem, já que dependem do repertório de significados que esta oferece. Assim, por exemplo, dizer que algo é bom ou belo só é possível no contexto de significados que determinada linguagem oferece - significados que não podem ser "possuídos" individualmente, mas só podem existir entre as pessoas. De modo semelhante aos nossos atos de fala que se situam na linguagem, nossas ações têm como pano de fundo determinadas práticas, instituições e compreensões compartilhadas.

Nessa mesma direção, Arendt mostra a importância da comunicação entre as pessoas. É por meio dela que, a princípio, podemos perceber que existe uma realidade na qual todos participamos. lsto é, a realidade das coisas não existe por si só. As coisas adquirem realidade quando aparecem a nós e quando notamos que não estamos sozinhos em nossa percepção, mas que a compartilhamos com outros, embora cada um veja as mesmas coisas a partir de sua perspectiva. Arendt (1983) explica que "a presença de outros que vêem o que vemos e ouvem o que ouvimos garante-nos a realidade do mundo e de nós mesmos" (p. 60). A possibilidade de estabelecermos uma realidade e comunicar-nos sobre uma mesma coisa está vinculada àquilo que Arendt (1995) chama de senso comum.

Por um lado, a realidade do que percebo é garantida por seu contexto mundano, que inclui outros seres que percebem como eu; por outro lado, ela é percebida pelo trabalho conjunto de meus cinco sentidos. 0 que, desde São Tomás de Aquino chamamos de senso-comum [...]. Esse mesmo sentido, um 'sexto sentido' misterioso, porque não pode ser localizado como um órgão corporal, adéqua as sensações de meus cinco sentidos estritamente privados [...] a um mundo comum compartilhado pelos outros. (p. 39)

A comunicação é, portanto, fundamental para que possamos estabelecer algo compartilhado por todos. É por meio dela que a sub- 
jetividade de nossas percepções adquire uma objetividade. Assim, a existência de uma diversidade de pontos de vista é constitutiva para o mundo comum, que partilhamos com nossos contemporâneos, mas também com aqueles que nos anteciparam e com os que darão continuidade à nossa ação depois de nós.

As crianças recém-chegadas neste mundo não o conhecem ainda. Por isso, é tarefa da educação apresentar-lhes o mundo. "Na medida em que a criança não tem familiaridade com o mundo, deve-se introduzi-la aos poucos a ele" (Arendt, 1990, p. 239). A educação é necessária não para preparar as crianças para a vida e suas necessidades, mas porque temos de introduzi-las a um mundo comum. Se não houvesse essa preocupação, bastaria que as crianças adquirissem as competências para sobreviver e para realizar seus projetos de vida individuais. lsso, entretanto, não quer dizer que os objetivos pessoais - como, por exemplo, se preparar para competir no mercado de trabalho - sejam irrelevantes ou devam ser excluídos da educação escolar, mas a educação como projeto da comunidade é necessária para introduzir as novas gerações naquilo que é comum. 0 mundo exige de nós um esforço educacional para ter continuidade, enquanto os interesses individuais são imediatos, ou seja, as necessidades vitais sempre serão prementes, mas não representam o que temos de mais valioso e especificamente humano. Dessa forma, Arendt (1990) afirma:

Se a criança não fosse um recém-chegado nesse mundo humano, porém simplesmente uma criatura viva ainda não concluída, a educação seria apenas uma função da vida e não teria que consistir em nada além da preocupação para com a preservação da vida e do treinamento e na prática do viver, que todos os animais assumem em relação a seus filhos. (p. 235)

Não preparamos as crianças apenas para funcionar e satisfazer suas necessidades e desejos, mas para que futuramente possam fruir e recriar o mundo.
As crianças, que ainda não assumem a responsabilidade pelo mundo, devem conhecêlo. Nesse sentido, Carvalho (s/d) explica que a educação tem por tarefa familiarizar os novos com "nossas heranças históricas comuns: a literatura e as artes, as ciências, a filosofia, os valores e práticas sociais por meio dos quais legamos a nossa compreensão do mundo e possibilitamos o surgimento de novas formas de expressão" (p. 2). Segundo Arendt (1990), mostrar o mundo para os novos é a tarefa dos mais velhos, que fazem parte deste mundo e são co-responsáveis por ele.

Face à criança é como se ele [o professor] fosse um representante de todos os habitantes adultos, apontando os detalhes e dizendo à criança: - Isso é o nosso mundo. (p. 239)

Assim, é tarefa da educação introduzir os novos num mundo que é mais velho e que precisa de nós para ser preservado. As crianças, que ainda não assumem responsabilidade pelo mundo, precisam se familiarizar com ele e apropriar-se de seus saberes e de suas práticas para que futuramente possam cuidar dele.

\section{Renovar o mundo}

Nosso mundo, entretanto, está "fora dos eixos". Cada vez mais os interesses privados tomam conta e se apoderam dos espaços, das práticas e dos significados compartilhados, que perdem assim seu sentido originário. Relacionado a isso está a perda do espaço público lugar de comunicação, de debate e de participação em projetos comuns. Assim as atividades especificamente humanas - que dizem respeito às relações entre as pessoas, às formas de convivência e ao sentido que estas dão à sua existência - têm perdido importância e cedido lugar a uma "lógica" utilitarista e à preocupação exagerada com a satisfação de necessidades reais ou inventadas. Ou para expressá-lo em termos arendtianos, as preocupações do trabalho e, sobretudo, do labor, ligado à pro- 
dução e ao consumo cada vez mais exacerbados, tomam conta do espaço da ação e da política, que deixa de cuidar do mundo para satisfazer necessidades.

A nossa "insatisfação com o mundo" e "o desgosto com o estado das coisas" (Arendt, 1990, p. 241), no entanto, não nos isentam da responsabilidade pelo mundo. Um traço característico do pensamento de Arendt é o "apesar de": Apesar de tudo - mesmo apesar da barbárie do mundo moderno -, precisamos apostar no mundo humano. Esse é o espaço humano e ao mesmo tempo humanizante. Contudo, o ser humano também é capaz de destruí-lo e, com isso, possibilitar a barbárie como, segundo Arendt (1990), ficou evidente nos regimes totalitários. Isso não deve ser esquecido nem desculpado, mas temos de encontrar formas de continuar convivendo neste mundo. É necessário, explica ela, nos reconciliarmos com o mundo - cenário do horror, mas também o único espaço que pode conferir dignidade a nossa existência. Cabe a nós a responsabilidade de arrumar esse lugar:

As palavras de Hamlet: - "The time is out of joint. 0 cursed spite that ever 1 was born to set it right" (0 tempo está fora dos eixos. ó ódio maldito ter nascido para colocá-lo em ordem) - são mais ou menos verídicas para cada nova geração, embora tenham adquirido talvez, desde o início de nosso século, uma validez mais persuasiva do que antes. (p. 242-243)

0 peso da responsabilidade, porém, é aliviado pela esperança que podemos ter pelo mundo. Talvez em lugar nenhum da obra de Arendt (1990) ela ganhe uma expressão tão forte quanto em seu ensaio sobre a educação, em que ela mostra que a esperança reside na natalidade: "o fato de todos nós virmos ao mundo ao nascermos e de ser o mundo constantemente renovado mediante o nascimento" (p. 247). Renovar o mundo é, a princípio, possível, porque cada ser humano que vem ao mundo é absolu- tamente singular - diferente de todos os outros que o antecederam, que convivem com ele ou que virão depois - e, devido a sua singularidade, cada um é potencialmente capaz de iniciar algo novo, isto é, algo que antes não existia e que, portanto, também não pode ser previsto.

0 fato de o ser humano ter o dom da ação, no sentido de fazer um início, só pode significar que ele foge a qualquer previsibilidade; que, nesse caso, a própria imprevisibilidade tem uma certa probabilidade e que aquilo que 'racionalmente' não é de se esperar pode mesmo assim ser objeto da nossa esperança. E esse dom para o imprevisível, por sua vez, se baseia exclusivamente na singularidade, por meio da qual cada um se distingue de qualquer um que foi, é ou será, [...] e essa singularidade se baseia no fato da natalidade, fundamental para toda comunidade humana, e em virtude da qual cada ser humano apareceu no mundo como um Novo singular. (Arendt, 1960, p. 167)

A educação que, por um lado, cuida do que é velho e de sua preservação, por outro lado, deve cuidar do novo, que vem ao mundo, e da singularidade que lhe é inerente. A singularidade, de certo modo, é o contraponto ao mundo comum. Precisamos proteger o novo contra o velho, porque a singularidade é muito frágil em relação ao peso do mundo.

Sendo ela [a criança] nova, deve-se cuidar para que esse novo ganhe apreço, conforme os critérios do mundo, e que não seja esmagado pela idade do mundo. (Arendt, 2000, p. 270)'

Assim, a criança pequena necessita de proteção contra o mundo para que possa desenvolver a sua singularidade. Nesse sentido, a

1. No texto em português, há a seguinte tradução, mais próxima da versão inglesa: "na medida em que ela [a criança] é nova, deve-se cuidar para que essa coisa nova chegue à fruição em relação ao mundo como ele é" (Arendt, 1990, p. 239). 
educação precisa oferecer um espaço onde as crianças e os jovens possam estabelecer relações - conhecer os outros e o mundo e se dar a conhecer - sem ainda estar sob o peso da responsabilidade pelo mundo. É no espaço entre as pessoas que a singularidade de fato se revela. Isso significa que a singularidade não teria nenhum valor se não convivêssemos com outros - no âmbito protegido da educação e, depois, no espaço público. Singularidade e pluralidade são dois lados de uma mesma moeda e ambas são essenciais para estabelecermos um espaço compartilhado.

\section{Singularidade versus personalidade}

A relevância da singularidade se mostra no espaço entre as pessoas e não fica restrita nem à interioridade nem ao espaço privado. Nesse sentido, é importante apontar que a singularidade não se refere nem à personalidade nem ao projeto de vida individual ou ao estilo de vida.

$\mathrm{Na}$ Condição humana, Arendt (1983) explica que "na ação e no discurso, os homens mostram quem são, revelam ativamente suas identidades pessoais e singulares" (p. 192). Aqui a autora aborda a singularidade no contexto da ação - constitutiva para o mundo. Ela deixa claro que não podemos conhecer nossa singularidade por meio de uma introspecção, já que ela não se situa num domínio interior nem está "a salvo" da convivência com os outros. A revelação da singularidade não está sob "controle" do indivíduo, mas é algo como um efeito não intencionado que ocorre no momento em que agimos em relação aos outros, isto é, em atos e palavras visíveis e audíveis. Assim, não é nem sequer a própria pessoa que, num primeiro momento, toma conhecimento de sua singularidade, mas são os outros que a percebem, antes dela mesma.

Esta revelação de 'quem', em contraposição a 'o que' alguém é - os dons, qualidades, talentos e defeitos que alguém pode exibir ou ocultar - está implícita em tudo o que se diz ou faz. [...] geralmente, porém, não basta o propósito deliberado de fazer tal revelação, como se a pessoa possuísse $\mathrm{e}$ pudesse dispor desse 'quem' do mesmo modo como possui e pode dispor de suas qualidades. Pelo contrário, é quase certo que, embora apareça de modo claro e inconfundivel para os outros, o 'quem' permaneça invisível para a própria pessoa, à semelhança do daimon, na religião grega, que seguia atrás de cada homem durante toda a vida, olhando-lhe por cima do ombro, de sorte que só era visivel para os que estavam à sua frente. (Arendt, 1990, p. 192)

A insistência da autora quanto à revelação da singularidade nas relações entre as pessoas, a meu ver, está relacionada com a sua problematização da idéia romântica da formação da personalidade. Arendt aborda esse tema nas Origens do Totalitarismo ao analisar a história dos judeus de exceção nos séculos que antecedem o totalitarismo. Sendo em sua grande maioria excluídos da sociedade, alguns judeus procuravam ingressar na alta sociedade por meio da formação, já que o status de "personalidade" lhes permitia a entrada nos salões. Procuravam assim uma solução individual para um problema político. 0 caminho escolhido era uma formação que enfatizava o potencial de desenvolvimento do indivíduo, sem considerar seu lugar no mundo. Mesmo assim, a formação, no final, servia como "ingresso" em determinados grupos sociais. Essa idéia era fortemente inspirada pelo romance de formação $O$ s anos de aprendizagem de Wilhelm Meister, de Goethe.

0 conceito de formação (Bildung) de Goethe, como é apresentado, sobretudo, em 'Wilhelm Meister', tornou-se o elemento de pensamento ao qual os judeus se assimilaram; sendo que, em 'Wilhelm Meister', a formação estava nitidamente ligada à ascensão social e ele, de fato, mostra como 'o burguês torna-se um aristocrata'. Por meio da formação esses ju- 
deus se tornavam 'personalidades', e todas as portas estavam abertas para a personalidade, conforme o ideal social da época. Por meio da formação - não por meios políticos como a emancipação - eles pretendiam escapar do status oprimido de seu povo. (Arendt, 2003, p. 152)

Arendt (2003) avalia essa concepção de formação como extremamente problemática, por ser apolítica. A preocupação dessas pessoas girava em torno do eu, sem perceber que seu problema não era individual nem poderia ser resolvido individualmente. Elas apenas "estavam ocupadas com seu desenvolvimento pessoal, a sua éducation sentimentale, o seu romance de formação (Bildungsroman)" (p. 151).

A autora, no entanto, tem certa admiração pela idéia de personalidade, o que fica evidente na história de Rahel Varnhagen - uma judia alemã, cuja biografia Arendt escreve - e em sua descrição do salão que ela mantinha em Berlim por volta de 1800 .

As soirées na 'mansarda' da Rahel reuniam não só os aristocratas 'esclarecidos' e os intelectuais da classe média, mas até atores e todos aqueles que, exatamente como os judeus, não pertenciam à sociedade respeitável. Assim, o salão de Rahel, por definição e intencionalmente, situava-se à margem da sociedade e não compartilhava quaisquer de suas convenções e preconceitos. (Arendt, 1989, p. 82)

Esse salão, no entanto, segundo Arendt (2003), representa um caso único na história dos judeus de exceção, porque havia nele uma busca autêntica da personalidade, sem a preocupação com o status social.

0 salão da Rahel [...] foi na história da assimilação e dos judeus de exceção uma figura absolutamente singular e única. 0 que mais tarde seria uma atitude mais ou menos hipócrita [...], aqui era realizado realmente e de modo singular e inocente: [...] aqui cada um era julgado somente por sua personalidade - e não por seu status [...] nem por seu dinheiro [...] - nem por seu sucesso na vida pública [...] - nem pela sua carreira literária. (p. 149)

Provavelmente o conceito de singularidade em Arendt - “quem" alguém é e não “o que" é - teve certa influência dessa aposta no potencial singular de cada pessoa. A autora, entretanto, critica a preocupação excessiva com o eu em detrimento da preocupação com o mundo, que resulta numa "cegueira" em relação à situação real das pessoas. Em oposição a isso, a singularidade arendtiana tem um sentido político, evidente no movimento da revelação. Algo que é inerente à pessoa - ela nasce singular - se revela, isto é, fica visível e, embora não possa ser descrito em termos de propriedades ou características, pode ser narrado em termos de uma história. Assim, atos e palavras singulares para Arendt têm muito mais em comum com a epopéia na qual o romance de formação se inspira do que com a concepção de personalidade desse tipo de romance. A diferença é que neste as experiências feitas pela pessoa servem principalmente para o enriquecimento e o desenvolvimento do eu interior, enquanto na epopéia é o outro que pode narrar os feitos e as experiências do herói. Morgenstern (apud Maas, 2005), que emprega o termo Bildungsroman, pela primeira vez estuda as relações entre a epopéia antiga e o romance burguês. Para ele, a epopéia mostra

[...] o protagonista agindo em direção ao exterior, provocando alterações significativas no mundo; o romance, por sua vez [mostra] os homens e o ambiente agindo sobre o protagonista, esclarecendo a representação de sua gradativa formação interior. Por isso mesmo, a epopéia apresentará antes os atos do herói com seus efeitos exteriores sobre os outros; o romance, ao contrário, privilegiará os fatos e os acontecimentos com seus efeitos interiores sobre o protagonista. 
Arendt (1960) se distancia claramente de uma interioridade, que leva a uma alienação do mundo. Na Condição Humana, ela mostra que a retirada para a subjetividade do "self" está relacionada à perda do senso comum. A fuga para a interioridade acontece, principalmente, nos momentos em que perdemos o que temos em comum. Assim, o declínio de senso comum é sinal de

[...] que aquilo que um grupo de homens tem em comum está desmoronando [...] e que, por isso, os homens estão se alienando do mundo e começaram a retirar-se para a sua subjetividade. (p. 203)

Temos de ter cuidado, portanto, em não confundir o conceito de singularidade com a subjetividade do "self" ou com a personalidade do romance de formação, já que a singularidade só se revela na convivência e comunicação com outras singularidades e não pode, de maneira alguma, ser entendida de modo separado do conceito de pluralidade.

Quanto à educação, isso mostra que o desenvolvimento da singularidade não diz respeito somente ao desenvolvimento psicológico, isto é, àquilo que acontece dentro da criança, mas à possibilidade de estar em relação com outros que possam reconhecê-la como pessoa. 0 desafio é criar um espaço onde as crianças possam se revelar na sua singularidade e no qual encontrarão o respeito dos outros pelo que são - na verdade, por quem são. Essa possibilidade remete a um aspecto essencial do espaço público - "o espaço potencial da aparência entre homens que agem e falam" (Arendt, 1983, p. 212) -, o qual se caracteriza por ser um lugar onde as pessoas se fazem ver e ouvir, onde são vistas e ouvidas.

A experiência do ser visto e ser ouvido como pessoa é fundamental, especialmente para os jovens cuja experiência no espaço social geralmente contrasta com isso. Nas relações sociais, o status, estreitamente ligado ao poder de consumo, é que é determinante para a ima- gem pessoal, isto é, para nosso "image". Arendt (1960) explica que na esfera social acontece uma identificação da pessoa com sua posição social. Jovens e crianças estão constantemente expostos a essa identificação, onde o que importa não é quem somos, mas o que somos e, muitas vezes mais ainda, o que possuímos ou aparentamos ter.

À tendência homogeneizadora do espaço social, Arendt (1983) opõe a pluralidade dos muitos singulares que convivem num mesmo espaço. Na vida escolar, cada criança certamente tem a experiência da pluralidade. Ainda protegida pela autoridade do adulto, a criança convive com pessoas diferentes dela, com as quais ela se comunica e pode fazer amizades. Essa riqueza inerente à convivência é muito significativa para a criança e é algo que ela mesma percebe e valoriza.

\section{Pluralidade versus pluralismo}

Nas reflexões pedagógicas, de modo geral, o tema da pluralidade está cada vez mais presente. Termos como multiculturalismo, diversidade cultural, etnia e culturas juvenis fazem parte dos discursos pedagógicos contemporâneos. Isso é reflexo de uma realidade na qual, de fato, convivemos com diferentes culturas, também no espaço escolar, especialmente na escola pública. Na maioria das vezes, destaca-se a importância de respeitar o diferente e de valorizar a diversidade. Isso certamente está em concordância com o conceito arendtiano de pluralidade. Precisamos, no entanto, tomar cuidado para não confundir a pluralidade em Arendt com concepções aparentemente semelhantes, mas que de fato apresentam diferenças fundamentais. Refiro-me à diferença entre singularidade/pluralidade e uma concepção de pluralismo que está estreitamente relacionada a um conceito de liberdade negativa, cujas raizes estão no liberalismo clássico.

2. 0 texto em português apenas fala da alienação, mas não da subjetividade (Arendt, 1983, p. 221). 
Um dos defensores desse tipo de pluralismo é lsaiah Berlin (2002). Ele parte do pressuposto de que todos somos diferentes e temos o direito de viver como quisermos, isto é, cada um é livre para conceber seu plano de vida com base em seus valores individuais. A liberdade é a ausência de imposições externas. Para garanti-la, devemos estabelecer uma ordem mínima que defina os direitos do indivíduo. Esses direitos asseguram a cada indivíduo uma área de não intervenção dentro da qual ele pode fazer o que quiser, escolher seu estilo de vida e procurar realizar seus propósitos. A liberdade, portanto, é, sobretudo, a liberdade do indivíduo que se localiza na vida privada. A ênfase está na não interferência.

Nessa concepção, certamente é possível que haja interesses convergentes, isto é, podemos agir junto com aqueles que têm interesses semelhantes aos nossos para somar forças. Entretanto, não pode haver projetos comuns a todos, porque não há nada com o qual todos possam concordar. Sustentar que há algum valor essencialmente comum é necessariamente omitir ou oprimir os valores daqueles que pensam diferente.

Esse conceito de liberdade negativa baseia-se na desconfiança em relação aos grandes ideais que possam inspirar projetos comuns. A liberdade, portanto, não tem lugar no mundo público, onde tratamos de assuntos comuns, mas fica restrita aos projetos individuais no âmbito da vida privada.

Para Arendt (1990), por outro lado, liberdade e pluralidade são conceitos que, antes de mais nada, dizem respeito ao âmbito público, o âmbito da ação. Em contraposição a Berlin, ela afirma que, na esfera da vida privada, não há liberdade, já que esse é o âmbito das necessidades ${ }^{3}$. Somente a libertação das necessidades vitais possibilita uma ação livre. Necessidades e desejos não apresentam singularidades, porque estão relacionados ao processo biológico. É justamente a capacidade de enxergar além da vida e de agir em relação aos outros, e junto com eles - criando formas de convivência -, que é especificamente humana e que nos distingue do resto da natureza, caracterizada pela causalidade. Arendt (2000) reconhece a legitimidade das liberdades individuais, mas liberdade e ação, na sua concepção, são essencialmente políticas.

Em nome do agir e do pensar, sem dúvida, a liberdade como realidade política é necessária. Essa liberdade política deve ser diferenciada dos direitos e das liberdades civis, que limitam o poder do governo em todos os estados de constituição e protegem o indivíduo em suas atividades privadas e sociais, legítimas. Tais direitos e liberdades são garantidos pelo corpo político, mas a vida e as atividades protegidas por eles não são políticas num sentido estrito. Do ponto de vista do âmbito político, são, portanto, liberdades negativas [...]. (p. 247-248)

Para Berlin (2002), a pluralidade, no que se refere à relação com os outros, constitui um problema, pois implica necessariamente na opressão dos diferentes, e conseqüentemente não há como ser livre no âmbito político. Ao contrário, a política, que sempre trata de assuntos e decisões que dizem respeito a todos, nega (ou ao menos diminui) a liberdade. A função que ela pode exercer é proteger o indivíduo em sua vida privada e social.

Arendt (1983), em contraposição, sustenta que sem pluralidade não haveria política - isto é, a preocupação com um mundo compartilhado. “[...] esta pluralidade é especificamente a condição - não apenas a conditio sine qua non, mas a conditio per quam - de toda vida política" (p. 15).

0 problema não está nos outros, e sim nos automatismos históricos. A singularidade de cada ser humano é tão importante por ser o pressuposto do seu potencial criador, mas o que o indivíduo cria é relevante não apenas para sua

3. Enquanto no seu ensaio 0 que é liberdade (1958, primeira versão do texto), Arendt ressalta a liberdade de ações visíveis no espaço público em oposição a uma liberdade interior, na Vida do Espírito (1971), ela explica que há uma liberdade filosófica, ligada à faculdade do querer. Esta, no entanto, diferente de uma liberdade interior de quem se retira do mundo, impele-nos para agir e começar algo novo. 
realização pessoal, mas também para a comunidade. Sua história singular se insere na história humana. Liberdade é um "não se contentar" com aquilo que é dado. Cada um terá a responsabilidade de pôr o mundo em ordem.

A liberdade em Arendt é política, porque está atrelada à preocupação com o mundo. Somos livres para modificar ou conservar o mundo e não para nos desfazer dele e cuidar de nossas vidas. A liberdade diz respeito à realização de nossos projetos para o mundo, que podem diferir dos meus projetos individuais ou dos do meu grupo social. Nisso não se trata simplesmente de descobrir um mínimo denominador comum para evitar conflitos de interesses, mas perceber que, ao participar num projeto comum, a nossa existência pode ganhar uma dimensão da qual ela carece na esfera dos interesses privados.

Além disso, parece-me extremamente relevante entender o conceito arendtiano de liberdade como um conceito temporal. Somos livres em relação ao passado e não em relação aos outros, já que ser livre é iniciar algo novo, mas a ação que realiza o novo sempre será uma ação conjunta, nunca individual.

0 mundo humano é ao mesmo tempo cenário e objeto da nossa liberdade. Isso significa que sem ele não haveria a possibilidade de agir livremente. Por isso, há um elemento conservador necessário à própria liberdade. Esta precisa do mundo e se destruímos esse espaço compartilhado e o pulverizamos, transformando-o numa sociedade atomizada, composta por grupos de interesses ou estilos de vida que não têm mais nada em comum a não ser a necessidade de se proteger uns dos outros, destruímos também a liberdade.

0 mundo comum, entretanto, não é inventado a cada geração, mas tem suas raizes na tradição e nos valores de uma comunidade. Esses laços, no entanto - que podem dar certa estabilidade ao mundo e proporcionar o terreno onde a liberdade pode se desenvolver -, romperam-se, isto é, perdemos o "corrimão" que a tradição nos oferecia. "Livres" do mundo, corremos o risco de nos tornarmos incapazes de agir com liberdade.
A educação se encontra na situação paradoxal de ter de introduzir as crianças num mundo que está "aos pedaços", mas sem o qual não se pode preparar os novos para agirem com liberdade. Qual a herança que entregaremos em suas mãos? Qual mundo eles renovarão?

Mesmo assim e apesar de tudo, explica Arendt - com uma teimosia que não abre mão da esperança -, a educação precisa mostrar que vale a pena apostar no mundo humano, isto é, não simplesmente descartar tudo, mas buscar o que possamos encontrar de valioso entre os escombros do mundo e confiá-lo aos mais novos, pois sua liberdade estará em transformar essa herança, o que não seria possível se não houvesse herança comum e se cada um pertencesse apenas a um grupo cultural ou de interesses.

Assim, Arendt (1990) se distancia claramente de alguns aspectos que correntemente associamos à liberdade. Liberdade, para ela, não pode ser restrita a uma disposição interior do espírito, pela qual estou livre para pensar o que quero independentemente daquilo que acontece no mundo. Também não se refere às possibilidades de realização no âmbito privado ou social, no sentido de que sou livre para conceber um plano de vida individual seguindo minhas próprias escolhas, mas somente quando há um mundo comum e um espaço público, isto é, um espaço onde podemos ver, discutir e realizar projetos que dizem respeito a todos. A liberdade pode de fato aparecer em atos e palavras singulares, mas preocupados com o mundo - e então os homens podem criar sua realidade.

A pluralidade para Hannah Arendt, portanto, é constitutiva para o ser humano. A convivência entre iguais, dos quais cada um é singular, é o que dá sentido à vida humana. As pessoas constituem um mundo comum com suas palavras e ações. Esse mundo, para a autora, é mais do que a soma de valores, bens e histórias individuais. Ele existe antes de cada indivíduo nascer e continuará depois dele morrer. Cada pessoa tem a responsabilidade de dar sua contribuição renovadora para que ele 
possa continuar existindo também depois dela. Já que a minha história individual é entrelaçada com outras histórias e com a história, não é possível dizer, pelos menos em alguns aspectos, que eu sozinha sou responsável pelos meus valores individuais e privados e que a minha ação não diz respeito ao mundo, mas apenas a mim mesma. Para Arendt (1983) - que sustenta que há bens, projetos e instituições que são essencialmente comuns e não apenas convergentes $^{4}-$, pluralidade e singularidade não representam obstáculos, mas pressupostos para a ação que busca estabelecer um mundo comum.

Quanto à educação, introduzir a criança no mundo e possibilitar o desenvolvimento da sua singularidade não são aspectos que se contradizem, mas são interdependentes. No que se refere à convivência com diversas culturas, isso significa que, por um lado, devemos reconhecer a riqueza que a diversidade traz para a convivência. Por outro lado, não é possível estabelecer um mundo comum sem que haja alguns princípios que todos reconhecem como válidos. Esse aspecto não deve ser compreendido apenas como uma concessão do indivíduo em relação à comunidade, mas é o que constitui o espaço público, onde singularidade e liberdade podem aparecer em atos e palavras.

\section{A educação entre o velho e o novo}

Na educação, as crianças vão conhecendo o mundo que é muito maior do que aquilo que já conhecem pela convivência familiar e social. 0 que lhes é mostrado, no entanto, é sempre o mundo do passado. "Dado que o mundo é velho, sempre mais que elas mesmas, a aprendizagem volta-se inevitavelmente para o passado" (Arendt, 1990, p. 246). Isso impõe limites para o educador. Este não pode prever o futuro nem tem como planejar ou controlar o futuro por meio da educação das crianças. Devido ao fato de que os homens sempre existem no plural, nunca poderemos controlar as ações dos outros, apenas lhes podemos mostrar que temos algo muito valioso em comum. Esse algo é o nosso mundo. 0 educador apenas dirá "Isso é o nosso mundo" (Arendt, 1990, p. 239), e não dirá como será o mundo. 0 que está por vir, ele deve confiar aos novos. A tarefa da educação é ajudar a preparar as crianças para assumir essa responsabilidade, mas a responsabilidade será delas e não pode ser antecipada na educação.

Nossa esperança está pendente sempre do novo que cada geração aporta; precisamente por basearmos a nossa esperança somente nisso, porém, é que tudo destruímos se tentarmos controlar os novos de tal modo que nós, os velhos, possamos ditar a sua aparência futura. (Arendt, 1990, p. 243)

Devido à capacidade de ação e ao dom da liberdade dos seres humanos, a história é absolutamente imprevisível. Não existem mecanismos ou leis históricas nem algo como um motor da história que, apesar de circunstâncias diversas, funcione sempre da mesma forma. É verdade que "os processos que denominamos históricos [...] tendem a se tornar tão automáticos como os processos cósmicos ou naturais" (Arendt, 1990, p. 217), mas os seres humanos, em contraposição à natureza, têm a possibilidade de romper com estes e começar algo completamente novo. Liberdade, nesse sentido, não é apenas optar ou escolher entre alternativas dadas, mas é

[...] chamar à existência o que antes não existia, o que não foi dado nem mesmo como um objeto de cognição ou de imaginação e que não poderia, portanto, estritamente falando, ser conhecido. (Arendt, 1990, p. 198)

A ação livre é imprevisível em dois sentidos. Por um lado, ela inicia o absolutamente novo, o que não pode ser pré-visto e, por outro lado, provoca outras ações que também não podem ser conhecidas ou planejadas antecipadamente, isto é, mesmo tendo as melho- 
res intenções, a pessoa não tem o controle das conseqüências de sua ação.

0 fato de que o homem não pode contar consigo mesmo nem ter fé absoluta em si próprio [...] é o preço que os seres humanos pagam pela liberdade; e a impossibilidade de permanecerem como senhores únicos do que fazem, de conhecerem as conseqüências dos seus atos e de confiarem no futuro é o preço que pagam pela pluralidade e pela realidade, pela alegria de conviverem com outros num mundo cuja realidade é assegurada a cada um pela presença de todos. (Arendt, 1983, p. 256)

Se a incontrolabilidade da ação possui, portanto, uma dimensão futura, a sua imprevisibilidade, ela se estende também para o passado: atos e palavras, uma vez realizados, não podem ser desfeitos, isto é, eles são irreversíveis. Somos obrigados a conviver com eles, mesmo que condenemos o ocorrido.

Para esses "males" da ação, Arendt (1983) propõe dois "remédios". A irreversibilidade dos atos passados pode ser remediada pelo perdão ou pela punição. Não são os atos que desculpamos, mas é possível perdoar (ou punir) os atores para assim possibilitar um novo começo nas relações que estabelecemos entre nós. A imprevisibilidade, por sua vez, tem por remédio a promessa. A exposição a um futuro desconhecido pode ser abrandada por acordos, contratos e leis. Esses compromissos não eliminam a incerteza do futuro, mas procuram mantê-la dentro de certos limites.

Tanto o perdão como a promessa dizem respeito a nossa responsabilidade pelo que fazemos. Isso significa que, embora não tenhamos o total controle das conseqüências de nossas ações, precisamos lidar com elas e encontrar respostas que viabilizem a continuidade do âmbito da ação e de nossa convivência.

As crianças que educamos, no entanto, ainda não assumem responsabilidade política e ainda não são totalmente responsáveis pelos seus atos. Antes de assumirem qualquer compromisso público, elas precisam conhecer este mundo que compartilham com os outros. Assim, o "remédio" contra a imprevisibilidade pouco ajuda nesse caso, já que ainda não podemos cobrar delas promessas que envolvem uma responsabilidade pelo mundo. Isso não significa desobrigar-nos perante elas e deixar que tudo se resolva por si, mas nos desafia a apresentar o mundo aos novos de tal modo que mais adiante se sintam impelidos a cuidar dele.

A educação, nesse sentido, não pode oferecer garantias para o futuro. Ao contrário, Arendt nos alerta que precisamos tomar cuidado de não impor às crianças aquilo que nós, a geração mais velha, pensamos ser um futuro "promissor". Dessa forma, transformaríamos as crianças num instrumento para os nossos objetivos. Poder-se-ia, entretanto, argumentar que fazemos isso para o seu bem, mas a nossa utopia sempre está relacionada à nossa experiência, e não podemos prever quais serão os ideais e as ações dos mais novos. A educação não é uma técnica que procura prever todas as variáveis possiveis de ação das gerações futuras, para daí guiar as crianças pela variável que julgar adequada. Ao contrário, a educação deve se voltar para o velho, que é o "chão" para o novo, mas que não o determina.

Arendt (1990) é bem clara a este respeito: "Exatamente em benefício daquilo que é novo e revolucionário em cada criança é que a educação precisa ser conservadora” (p. 243).

As variáveis futuras são infinitas, porque os seres humanos são capazes não apenas de escolher entre alternativas dadas, mas de criá-las com sua ação. De certo modo, a educação aumenta ainda mais a imprevisibilidade do futuro, porque prepara as crianças para agir livremente, isto é, para começar o novo que, por se tratar de crianças, sequer pode ser contido por promessas. É, entretanto, nessa imprevisibilidade assustadora que reside nossa esperança de um mundo melhor. 


\section{Referências bibliográficas}

ARENDT, H. A condição humana. Tradução de Roberto Raposo. Rio de Janeiro: Forense Universitária, 1983.

Elemente und Ursprünge totaler Herrschaft. 9. ed. Munique: Piper, 2003.

Entre o passado e o futuro. São Paulo, Perspectiva, 1990.

Origens do totalitarismo. Tradução de Roberto Raposo. São Paulo: Companhia das Letras, 1989.

A vida do espírito. Tradução de Antonio Abranches e Helena Martins. Rio de Janeiro: Relume Dumará, 1995.

Vita activa oder Vom tätigen Leben. Munique: Piper, 1960.

Zwischen Vergangenheit und Zukunft: Übungen im politischen Denken I. 2. ed. Munique: Piper, 2000.

BERLIN, I. Dois conceitos de liberdade. In: HARDY, H. (Org.). Estudos sobre a humanidade. São Paulo: Companhia das Letras, 2002. p. 226-272.

CARVALHO, J. S. A liberdade educa ou a educação liberta? Mimeo.

MAAS, W. P. M. D. 0 romance de formação (Bildungsroman) no Brasil. Modos de apropriação. Caminhos do Romance. 2005. Disponível em <http://www.caminhosdoromance.iel.unicamp.br>. Acesso em: 05 mar. 2008.

TAYLOR, C. Bens irredutivelmente sociais. In: . Argumentos filosóficos. Tradução de Adail Ubirajara Sobral. São Paulo: Loyola, 2000. p. 143-161.

Recebido em: 17.03 .08

Aprovado em: 23.10 .08

Vanessa Sievers de Almeida, bacharel em Teologia (Faculdade de Teologia da Igreja Metodista), licenciatura plena em Pedagogia (FEUSP), doutoranda do Programa de Pós-Graduação (FEUSP), com bolsa da FAPESP, foi assessora pedagógica em ONG e atuou como tradutora e professora de alemão. 